\title{
ACIDENTES DOMÉSTICOS EM CRIANÇAS: CONCEPÇÕES PRÁTICAS DOS AGENTES COMUNITÁRIOS DE SAÚDE*
}

Maria Augusta Rocha Bezerra', Ruth Cardoso Rocha², Fabyanna dos Santos Negreiros ${ }^{3}$, Fernanda Miranda Oliveira de Morais Lira ${ }^{3}$, Luzicleia Tavares de Sousa ${ }^{4}$, Sabatha Coelho Gomes Santiago ${ }^{4}$

${ }^{1}$ Enfermeira. Mestre em Saúde da Criança e do Adolescente. Universidade Federal do Piauí. Floriano-PI-Brasil ${ }^{2}$ Enfermeira. Especialista em Gestão em Programa Saúde da Família. Universidade Federal do Piauí. Floriano-PI-Brasil ${ }^{3}$ Discente de Enfermagem. Universidade Federal do Piauí. Floriano-PI-Brasil

${ }^{4}$ Enfermeira. Universidade Federal do Piauí. Floriano-PI-Brasil

RESUMO: Pesquisa qualitativa do tipo descritivo-exploratória, que objetivou compreender a atuação prática dos Agentes Comunitários de Saúde diante dos acidentes domésticos em crianças menores de cinco anos, desenvolvida com oito profissionais cadastrados em uma Unidade Básica de Saúde do município de Floriano, Piauí. Os dados foram coletados em março de 2014, tendo como método a pesquisa-ação e analisados segundo análise temática, na qual emergiram três categorias: Vigilância do ambiente domiciliar, Estratégias educativas destinadas aos cuidadores e Condutas diante da ocorrência de acidentes. Os dados demonstram ser imprescindível o planejamento de uma metodologia apropriada para ser desenvolvida com os Agentes Comunitários de Saúde, que favoreça a qualificação da sua prática no âmbito da saúde da criança no contexto dos acidentes domésticos. Estes resultados podem contribuir para uma rediscussão das práticas de Educação Permanente em Saúde e fomentar o investimento dos gestores do Sistema Único de Saúde, em ações educativas formadoras e emancipadoras. DESCRITORES: Acidentes domésticos; Criança; Agentes comunitários de saúde.

\section{DOMESTIC ACCIDENTS AMONG CHILDREN: PRACTICAL CONCEPTIONS OF COMMUNITY HEALTH WORKERS}

\begin{abstract}
This qualitative, descriptive-exploratory research aimed to understand the practical work of the Community Health Workers regarding domestic accidents among children below five years old. It was undertaken with eight professionals registered in a Primary Healthcare Center in the municipality of Floriano, in the Brazilian State of Piauí. The data were collected in March 2014, the method was action-research, and the data were analyzed in accordance with thematic analysis, in which three categories emerged: Surveillance of the domestic environment, Educational strategies aimed at the caregivers, and Conducts regarding the occurrence of accidents. The data show that it is essential to plan an appropriate methodology to be undertaken with the Community Health Workers, which favors the qualification of their practice in the ambit of children's health in the context of domestic accidents. These results may contribute to the rediscussion of the Continuous Education in Health practices and encourage investment from the managers of the Unified Health System in formative and emancipatory educational actions. DESCRIPTORS: Domestic accidents; Child; Community health workers.
\end{abstract}

\section{ACCIDENTES DOMÉSTICOS CON NIÑOS: CONCEPCIONES PRÁCTICAS DE LOS AGENTES COMUNITARIOS DE SALUD}

RESUMEN: Investigación cualitativa del tipo descriptivo y exploratorio, cuyo objetivo fue comprender la actuación práctica de los Agentes Comunitarios de Salud delante de los accidentes domésticos con niños de hasta cinco años, desarrollada con ocho profesionales registrados en una Unidad Básica de Salud del municipio de Floriano, Piauí. Los datos fueron obtenidos en marzo de 2014 y el método utilizado fue el de la investigaciónacción, siendo observados de acuerdo al análisis temático, del cual resultaron tres categorías: Vigilancia del ambiente domiciliar, Estrategias educativas destinadas a los cuidadores y Conductas delante de la ocurrencia de accidentes. Los datos muestran ser imprescindible el planeamiento de una metodología adecuada a ser desarrollada con los Agentes Comunitarios de Salud, que favorezca la cualificación de la práctica en el ámbito de la salud del niño en el contexto de los accidentes domésticos. Los resultados pueden contribuir para una nueva discusión de las prácticas de Educación Permanente en Salud y fomentar la inversión de los gestores del Sistema Único de Salud, en acciones educativas formadoras y emancipadoras. DESCRIPTORES: Accidentes domésticos; Niño; Agentes comunitarios de salud. 


\section{INTRODUÇÃO}

Na infância, em especial na fase pré-escolar, as causas externas têm sido cada vez mais responsáveis pelas lesões e óbitos que acometem inúmeras crianças no Brasil e no mundo. Devido ao conjunto de características que as tornam mais vulneráveis aos acidentes, como a imaturidade física, mental e comportamental(1); as crianças ficam mais propensas aos acidentes domésticos como quedas, ferimentos causados por objetos cortantes, intoxicações, choques e queimaduras ${ }^{(2)}$.

Atualmente, os acidentes domésticos em crianças menores de cinco anos são apontados como uma das principais causas de mortalidade e morbidade na população com idade entre um a 14 anos em todo o mundo ${ }^{(2)}$. Consistem em situações complexas e revelam um grave problema de saúde pública, pois além dos custos sociais, econômicos e emocionais, são também responsáveis por eventos não fatais e sequelas que, em longo prazo, repercutem na família e na sociedade, penalizando crianças e adolescentes ${ }^{(3)}$.

Quanto ao contexto internacional do problema, uma pesquisa realizada na cidade de Kampala na África, com crianças menores de 13 anos, que foram involuntariamente feridas, referiu que dos 556 pacientes registrados no hospital, 47\% eram menores de cinco anos. Em relação aos ambientes domésticos, estes representaram $54,8 \%$ dos locais de maior ocorrência de lesões não intencionais na infância ${ }^{(4)}$. No Brasil, um estudo realizado com 7.123 crianças de idade inferior a 10 anos, evidenciou que $96,8 \%$ foram vítimas de acidentes, a maioria das ocorrências $(66,6 \%)$ incidiu no domicílio, tendo o corte como lesão mais frequente (35,7\%). Além disso, do total de crianças, 18,9\% tinham até um ano de idade e $41,6 \%$ de dois a cinco anos, portanto, $60,5 \%$ possuíam até cinco anos de idade ${ }^{(3)}$.

Diante desta problemática, os profissionais da saúde têm uma grande responsabilidade na orientação e alerta das famílias, pois são interventores ativos na mudança de comportamentos e atitudes, no sentido da prevenção de acidentes e minimização das consequências que deles podem advir ${ }^{(5)}$. Desse modo, para que o cuidador possa exercer as condutas necessárias para prevenir agravos na infância, é imprescindível que sejam intensificadas ações de educação, individual ou coletiva, necessitando da atuação dos profissionais envolvidos nessa realidade ${ }^{(6)}$.

Dentro do contexto da Atenção Primária à Saúde, o Agente Comunitário de Saúde (ACS) irrompe como um componente importante, tanto na perspectiva da vigilância, incluindo a detecção de ambientes propícios aos acidentes com crianças e a orientação de medidas preventivas; como no manejo dos casos em que não foi possível evitá-los. O ACS passa a ser uma personagem de grande significância para o nível primário de atenção à saúde, devido a sua proximidade com a comunidade configurando-se no elo entre a equipe de saúde e a população(7), contribuindo, na implementação de intervenções preventivas ao contexto domiciliar.

Tendo em vista a relevância do papel que os ACS assumem dentro da equipe de saúde e do seu potencial em identificar os fatores de riscos para a criança em sofrer acidentes em seus domicílios, faz-se necessário depreender a sua atuação diante desta temática, a fim de elencar subsídios que auxiliem na melhoria das estratégias preventivas. Mediante as considerações expostas, emergiu a seguinte questão norteadora da pesquisa: Como os ACS atuam na perspectiva da segurança da criança no ambiente domiciliar?

Portanto, o presente estudo teve como objetivo compreender a atuação prática dos ACS diante dos acidentes domésticos em crianças menores de cinco anos.

\section{MÉTODO}

Trata-se de uma pesquisa de natureza qualitativa, do tipo descritivo-exploratória, vinculada a um projeto de pesquisa cadastrado na Pró-reitoria de Pesquisa da Universidade Federal do Piauí, intitulado "Acidente ou descuido: o ambiente domiciliar e seus fatores de risco para traumatismos em crianças". A coleta de dados, fase exploratória da pesquisa-ação, ocorreu no mês de março de 2014.

O estudo foi realizado em uma Unidade Básica de Saúde, da cidade de Floriano- PI. Os participantes do estudo foram oito ACS, cadastrados à referida unidade. Vale ressaltar que o quantitativo total de nove ACS que prestavam serviços à comunidade não foi alcançado, pois um desses recusou-se a participar.

Para a consolidação da amostra, foi utilizado 
o processo de amostragem e representatividade para delimitar o campo de observação empírica ${ }^{(8)}$. Esta foi composta por todos os ACS que compareceram à reunião ou foram posteriormente abordados e que, voluntariamente, aceitaram participar da pesquisa e das estratégias de coleta dos dados. Foi utilizado como critério de inclusão: ACS devidamente cadastrado na Estratégia de Saúde da Família, realizando atividades há no mínimo um ano.

Para a coleta de dados foram utilizados o referencial do método pesquisa-ação. A técnica empregada foi a entrevista individual aplicada de modo aprofundado ${ }^{(8)}$. Para sua consecução, utilizou-se na fase exploratória um roteiro contendo informações acerca dos aspectos sociodemográficos dos participantes do estudo e questões norteadoras que abordaram as concepções teóricas e práticas do ACS sobre os acidentes domésticos, envolvendo crianças menores de cinco anos, sendo que este manuscrito apresenta o recorte relativo aos aspectos práticos.

Ressalta-se que não houve monopolização na construção (procedimentos de coleta) dos resultados pelos pesquisadores. Neste sentido, os participantes não foram considerados apenas como membros informantes, ou seja, procurouse articular as etapas da pesquisa de modo que eles também desempenhassem uma função interrogativa, com a possibilidade de fazer perguntas e elucidar os assuntos coletivamente inquiridos. Desse modo, os ACS levantaram problemas e situações de suas práxis profissionais com as famílias que cuidam, e estas informações geraram os constructos desta investigação ${ }^{(8)}$.

As respostas colhidas foram organizadas, seguindo as temáticas procedentes das perguntas norteadoras do estudo, e na análise foram interpretadas as concepções práticas do ACS quanto ao acidente doméstico em crianças menores de cinco anos. Para o início da análise das informações dos ACS, as falas foram ouvidas e transcritas na íntegra, tendo o conteúdo sido analisado em três etapas. Primeiramente foi feita uma pré-análise através de leitura flutuante do material. Em seguida, foi realizada a exploração do material para definição das categorias e, por fim a condensação das informações para interpretação reflexiva e crítica. O critério de categorização utilizado e que permeou todo o processo foi semântico, estabelecendo-se categorias temáticas que reuniram as unidades de registro sob títulos genéricos ${ }^{(9)}$, que foram elencadas como: Vigilância do ambiente domiciliar; Estratégias educativas destinadas aos cuidadores e Condutas diante da ocorrência de acidentes.

Esta investigação respeitou as normas éticas para execução de pesquisas com seres humanos $^{(10)}$ e foi aprovada pelo Comitê de Ética em Pesquisa da Universidade Federal do Piauí, por meio do parecer 530.717/2014.

\section{RESULTADOS}

Nesta pesquisa, foram entrevistados oito ACS, compostos por seis trabalhadores do sexo feminino e dois do sexo masculino, com faixa etária variando entre 32 a 47 anos, predominantemente casados. Sobre o grau de escolaridade, todos possuíam o ensino médio completo, três apresentavam curso técnico e um estava concluindo o curso superior. A maioria não exercia outra função e trabalhava na profissão há mais de dez anos. Dois ACS relataram realizar atividades extras para complementar a renda familiar mensal que variou de um a três salários mínimos.

Quanto à realização de cursos e capacitações direcionados à saúde da criança os ACS referiram ter realizado poucos cursos apontando uma maior predominância de cursos sobre atualização em calendário de vacinas, acompanhamento de crescimento, peso (principalmente relacionado à desnutrição), condutas em casos de diarreias e febre.

Na categoria Vigilância do ambiente domiciliar, observou-se que os fatores de riscos existentes no ambiente domiciliar são variados. Esta diversidade foi revelada pelos discursos dos ACS, que citaram vários locais observados durante as visitas domiciliares, propícios para ocorrência de acidentes, havendo destaque para cozinha e a sala. No que concerne à cozinha, os ACS destacaram que observam em seu exercício profissional, diversos materiais, instrumentos e situações que podem predispor ao acidente doméstico envolvendo crianças:

[...] na cozinha tem faca, isqueiro, fósforo [...] a pessoa risca e deixa jogado em todo lugar. (ACS I) 
[...] Panela mal posicionada com o cabo pra fora, facas [...]. (ACSII)

[...] eu observo mais as cozinhas [...] a cozinha se não tem alguma coisa ali por perto da pia, do fogão, criança geralmente tem a tendência a pegar coisas no armário [...], ele pode pegar na geladeira que está descascada [...]. (ACS IV)

\section{[...] Panela com o cabo para fora [...] ela pode} pegar no cabo, virar por cima dela, provocar uma queimadura. (ACS VI)

Quanto ao ambiente da sala - segundo lugar mais observado - os ACS demonstraram perceber principalmente, instalações elétricas ao alcance das crianças, disposição de eletrodomésticos com livre acesso e assentos como sofá como fatores que predispõem a choques e quedas:

[...] Na sala, por exemplo, a criança com tomadas baixas, vai lá e mete o dedo [...] deixa a criança assistindo televisão na sala sozinha e às vezes ela vai querer meter e tirar a tomada toda hora. (ACS I)

[...] costumo observar só as tomadas [...] onde estão instaladas as tomadas [...] quando eu vejo assim uma tomada assim baixinha, eu costumo ficar olhando [...] gente compra uns protetores para essas tomadas, isso aí é um maior perigo é essas tomadas [...] o que me chama mais atenção é isso aí, quando eu vejo umas tomadas baixinhas dentro de uma casa, eu gosto de observar esse detalhe. (ACS III)

[...] um sofá que vai sentar, para se sentar tem criança que cai. (ACS VII)

Na categoria Estratégias educativas destinadas aos cuidadores, os ACS fizeram relatos diversificados em relação ao tema, evidenciando que possuem conhecimentos sobre algumas medidas preventivas contra acidentes domésticos e que orientam os cuidadores para adoção de tais condutas, no intuito de evitar os fatores de riscos para acidentes como intoxicação por produtos de limpezas e medicamentos, choques elétricos e afogamentos:
[...] quando eu vejo muito exposto esses materiais de limpeza - oh mãe guarda esse material de limpeza em outro lugar ali pro bebê não pegar[...]. (ACS III)

[...] o medicamento, já é um risco né pra criança poder pegar e se intoxicar com a medicação se ficar fácil [...] que tem criança quando ver um comprimido nossa, já quer tomar um! [risos] e se for um AAS infantil, vixe [...]. (ACS VII)

[...] gente compra uns protetores para essas tomadas, isso aí é um perigo é essas tomadas! (ACSIII)

[...] tomadas, colocar mais pra cima [...] vamos levantar essa tomada [...]. (ACS VI)

[...] Precisa guardar água? Precisa. Vamos ter cuidado, amarrar [...] tampar bem (o balde) direitinho, para que a criança não possa mexer, não possa cair dento[...]. (ACS VI)

Em outras falas, os participantes descreveram estratégias para prevenir queimaduras, cortes e quedas:

[...] se cozinha no carvão, né vamos fazer o seguinte [...] terminou de cozinhar, apaga o fogo [...] vamos colocar as panelas assim (gesto de posicionar os cabos para dentro do fogão) [...] cuidado para não cair por cima [...]. (ACS VI)

[...] Orientações, para ter mais cuidado, para não deixar fácil, para criança não ter acesso, observar bem com o que ela está brincando, as vezes até tesoura [...] tem a ponta fina e tem umas que é cortante, aí a gente sempre fala para guardar em lugares adequados, para não deixar fácil [...] não deixar as coisas ao alcance das crianças[...]. (ACS VII)

[...] o berço pra que fique mais profundo e ela não chegue a perna em cima [...] em caso de criança que dorme em rede [...] mas tem uma rede é botar a rede o mais baixo possível né? [...] porque mesmo que ela caia é de uma quedinha menor [...] mais leve [...]. (ACS VI) 
[...] queda de criança, às vezes ele desloca o braço, a perna [...] Orientei pra eles terem mais atenção, não deixar subir nas arvores [...] então na época que tiver fruta, em vez dele esperar ele subir, ele vai lá e pega pra criança. (ACS II)

A categoria Condutas diante da ocorrência de acidentes, procura apresentar os tipos de acidentes que incidiram na área dos ACS, bem como a conduta praticada diante da ocorrência dos mesmos. Quanto a episódios de quedas e as condutas no momento do ocorrido os ACS relataram os seguintes casos:

Quedas [...] da calçada pro chão pegou não sei quantos pontos [...] era muito sangue [...] aí eu mesmo peguei assim um paninho pra tentar estancar mais o sangue né [...] e chamamos o SAMU e tudo aí [...] levaram pro hospital. (ACS III)

[...] quedas, justamente desse tipo, a criança caiu e quebrou o braço [...] caiu da rede, caiu por cima do braço [...] não colocou mais a criança na rede, colocou a criança na cama [...] ter mais atenção. (ACS IV)

Em relação à ocorrência de queimaduras, foi narrado o seguinte evento:

[...] Uma panela de água, subiu no banco, e puxou o cabo da panela [...] era uma leiteirazinha, era uma leiteira, ela se queimou todinha, até hoje tem a cicatriz [...]. Foi, a mãe correu lá em casa que tava toda vermelhazinha já encaminhou ela direto pro hospital. (ACSV)

No que concerne à ocorrência de choques elétricos e condutas diante da situação, os ACS relataram que encaminharam para a unidade hospitalar, e fizeram orientações necessárias para o aumento da supervisão da criança, bem como mudanças na estrutura do domicílio e descarte de eletrodomésticos defeituosos para evitar novos acidentes:

[...]. Choque, já aconteceu [...] a menina é sequelada até hoje [...] nesse caso foi imediatamente levar pro hospital [...] deixasse no máximo longe de energia [...] o segundo caso ele foi pegar no ventilador, levou um choque no dedinho [...] inclusive queimou o dedinho dele [...] colocar as tomadas altas, tirar ventilador. (ACS VI)

Quanto à ocorrência de engasgo/asfixia e o manejo de vítimas nesta ocorrência, os ACS referiram os seguintes episódios:

[...] o menino engoliu pedaço de folha, não sei como foi, só sei que essa folha não desceu e, o menino ficou com falta de ar e, ficou sufocado, acho que era uma folha peluda [...] e eu pegava essa criança e levantava né! Me lembrei daquele negocio lá [tenta simular a manobra de Heimlich, mas de forma inadequada] como salvar recémnascido, aí eu lembrei e fiz a manobra nele e levantava o braço dele, aí que outra vizinha minha chegou [...] deu água pra criança [...] aí outra vizinha chamou o SAMU mas antes do SAMU chegar outra vizinha já tinha conseguido tirar [...] puxou. (ACS III)

[...] minha neta se engasgou com remédio pequenininha [...] a menina faltava o ar sem respirar...lá vou eu de novo na técnica...aí foi que eu peguei ela, botei aqui nos peitos, apertei levantei os bracinhos dela, aí foi que ela suspirou fundo. Esses acidentezinhos assim que deixa a pessoa em maus momentos! Se você não souber agir na hora, você termina perdendo a cabeça e as vezes entra até em óbito. (ACS III)

\section{DISCUSSÃO}

No que concerne à categoria Vigilância do ambiente domiciliar, verifica-se que a sala e a cozinha são os ambientes mais observados por estes profissionais. Entretanto, a pouca ou mesmo ausente referência sobre a observação no que diz respeito aos outros locais que propiciam riscos de acidentes domésticos em crianças revela uma lacuna sobre os seus conhecimentos.

Um estudo para identificar os locais de ocorrência de acidentes domésticos em crianças, divulgou a sala como o principal ambiente de ocorrência de acidente no ambiente domiciliar ${ }^{(11)}$. Constatou-se que a presença de fios soltos e tomadas das paredes sem protetores especiais e posicionadas ao alcance das crianças, pode 
desencadear em choque elétrico ${ }^{(12)}$. Identificouse também, a cozinha como lugar mais perigoso do ambiente doméstico para a criança, porque é nela que ocorre a maioria das queimaduras, lesões cortantes, lacerações e intoxicações, entre outros acidentes ${ }^{(13-14)}$. Fatores estes que foram citados pelos ACS e observados durante as visitas domiciliares da sua área de abrangência.

Percebe-se a importância da observação realizada pelos ACS nesses cômodos, para que assim possam ser mediadores de informações aos cuidadores - visando a adoção de medidas que reduzam os riscos para acidentes nesses ambientes. Porém houve poucos relatos dos participantes sobre a análise de outros cômodos do ambiente doméstico que também trazem riscos para uma criança, como: quarto, banheiro, área de serviço e quintal.

Quanto à categoria Estratégias educativas destinadas aos cuidadores, compreendeu-se também que os ACS possuem conhecimentos sobre determinadas medidas preventivas contra acidentes domésticos e que orientam os cuidadores para adoção de tais medidas quando identificados os fatores de risco. Tais ações corroboram com algumas recomendações preconizadas pelo Ministério da Saúde para orientar o ACS na promoção da segurança das crianças no ambiente domiciliar ${ }^{(15)}$.

Diante da ocorrência de acidentes domésticos envolvendo crianças, os ACS devem estar preparados para atuar por intermédio de medidas que podem, se realizadas adequadamente, evitar sequelas e até mesmo óbitos, ressaltando que uma conduta inadequada pode acarretar consequências irreversíveis. No tratamento de emergência das queimaduras, recomendase: limpar a ferida com água e sabão neutro; não colocar gelo, qualquer produto químico sobre a região lesada, isso pode agravar a área queimada ${ }^{(16)}$.

Riscos de engasgos e sufocação também podem ocorrer no domicílio. Cerca de $80 \%$ dos casos de aspiração de corpo estranho ocorrem em crianças, com um pico de incidência entre um e três anos. Nessa faixa etária, as crianças exploram o mundo através da via oral, possuem coordenação motora fina para colocar um pequeno objeto na boca, no entanto, quando um objeto grande é aspirado, causa dificuldade respiratória, afonia, cianose, podendo rapidamente ser letal. Nesses casos devem ser empregadas medidas como tapas nas costas em lactente ou o emprego da manobra de Heimlich em crianças maiores ${ }^{(17)}$.

Percebeu-se que a prática do ACS no que diz respeito ao acidente doméstico com criança está direcionada àqueles tipos de acidentes mais comuns, não sendo citados dentro das estratégias de educação em saúde alguns acidentes de grande relevância na infância pelo seu potencial de causar sequelas e óbitos, como os acidentes por sufocação, asfixia e estrangulamento.

Dentro da categoria Condutas diante da ocorrência de acidentes, pode-se compreender que algumas condutas dos ACS diante da ocorrência dos tipos de acidentes citados foram adequadas. Observa-se limitação na falta de conhecimento teórico e técnico sobre as noções de primeiros socorros. Para isso há necessidade de cursos de atualização em primeiros socorros e manejo eficiente perante as condições de emergências, sendo sugerido inclusive pelos próprios ACS, a inclusão da temática primeiros socorros, como disciplina do Curso Técnico em Agente Comunitário de Saúde ${ }^{(18-19)}$.

Diante dos resultados percebeu-se a ausência de cursos direcionados aos ACS para a prevenção de acidentes domésticos, havendo para este assunto apenas relatos de atualizações em primeiros socorros. É imprescindível destacar que a prevenção de acidentes domésticos envolvendo crianças deve fazer parte da formação destes profissionais, conforme determina a publicação ministerial Guia Prático do Agente Comunitário de Saúde ${ }^{(15)}$. Entretanto, é possível afirmar que a ênfase é dada aos aspectos epidemiológicos e de vigilância à saúde ${ }^{(20)}$.

Sabe-se que o processo de formação deste profissional, ainda incipiente, contribui para que lacunas no conhecimento impossibilitem que atividades relativas à prevenção de acidentes domésticos envolvendo crianças sejam realizadas de forma consistente e embasadas por conhecimentos teórico-práticos. Assim é necessário um treinamento adequado, no qual sejam abordadas situações de risco por meio de oficinas práticas com simulações, para que o socorro à vítima e as manobras utilizadas em situações de risco de morte, referidas pelos participantes, possam ser realizados a partir de um adequado entendimento e fundamentação ${ }^{(21)}$. 
Destarte, além da capacitação dos ACS, devem ser incrementadas as ações de orientação e empoderamento das famílias em proteger suas crianças eprevenir acidentes, considerando o protagonismo dos cuidadores em contribuir com o direito da criança em gozar bem-estar físico e ter sua saúde promovida ${ }^{(22)}$.

Todas estas questões demandam um compromisso político-programático dos gestores do Sistema Único de Saúde (SUS) e supervisores dos ACS que garantam uma formação adequada a estes profissionais, assim como estratégias de educação permanente para as equipes de Saúde, quanto ao cuidado integral à criança ${ }^{(23)}$.

Diante da discussão realizada, este estudo apresenta, para melhor compreensão do leitor, uma síntese das categorias dos achados desta pesquisa e suas proposições, na matriz apresentada na Figura 1, a seguir:

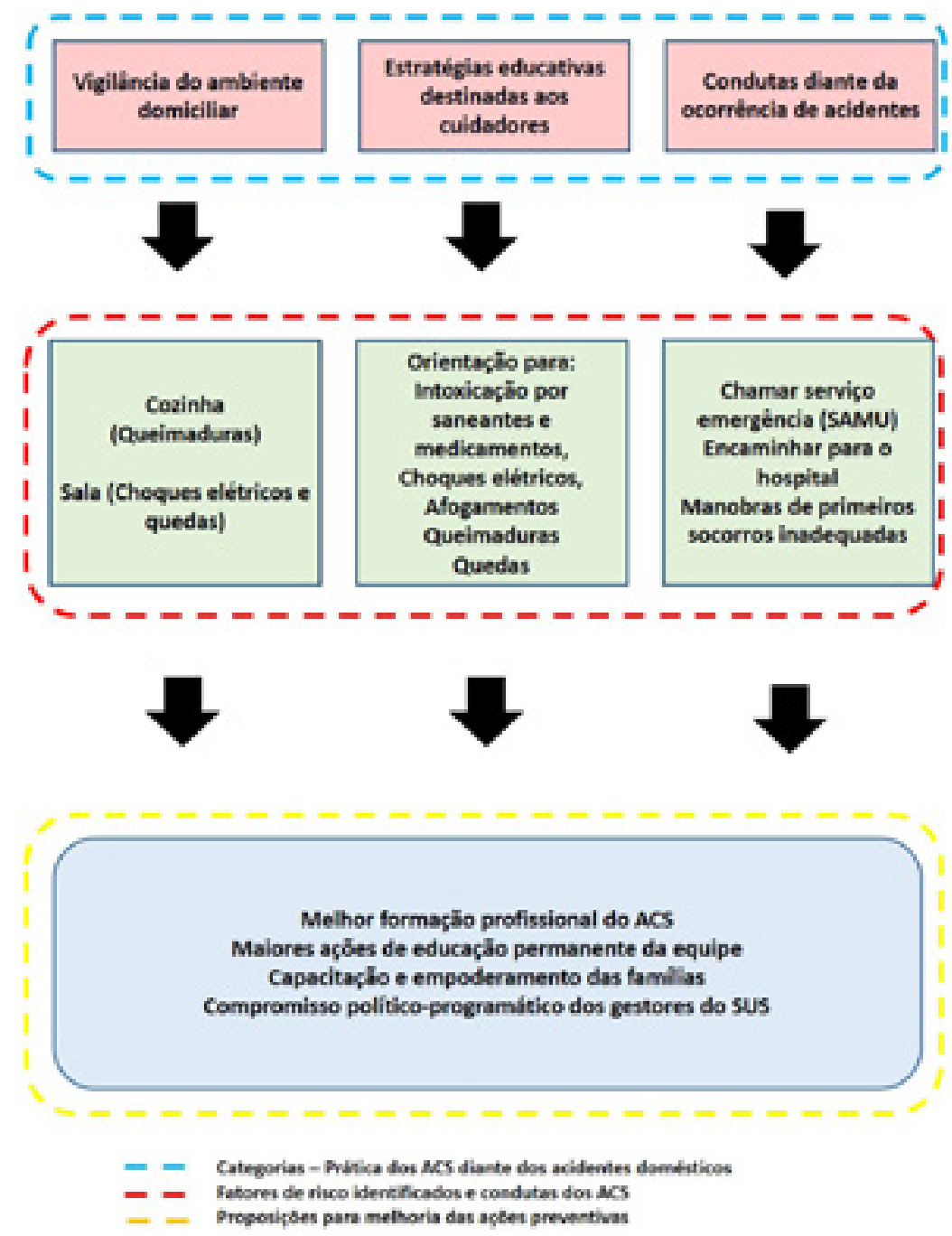

Figura 1 - Aspectos da atuação dos ACS diante dos acidentes domésticos, e as proposições para melhorias das práticas preventivas. Floriano-PI-Brasil, 2014

\section{CONSIDERAÇÕES FINAIS}

Os dados desta pesquisa evidenciaram que as estratégias de intervenção dos ACS diante de acidentes domésticos com crianças estão enfocadas em três dimensões principais: na observação do ambiente, na orientação das medidas de proteção e no manejo diante da ocorrência do acidente. No entanto, lacunas importantes em sua prática foram evidenciadas, demonstrando um conhecimento construído muito mais pela vivência empírica do que proveniente de uma formação específica e consistente.

Novas pesquisas de cunho intervencionista devem ser desenvolvidas em outras realidades que permitam a reorientação do modelo de atenção das equipes quanto à prevenção de acidentes na infância. Este estudo possui limites de alcance, pois foi construído com dados qualitativos de um contexto específico de uma região do Brasil. 
Destarte, estes resultados podem contribuir para uma rediscussão das práticas de Educação Permanente em Saúde e fomentar o investimento dos gestores do SUS, em ações educativas formadoras e emancipadoras e em metodologias apropriadas para serem desenvolvidas com os Agentes Comunitários de Saúde, que favoreçam o fortalecimento de suas práxis assistenciais para o benefício da comunidade em geral.

\section{REFERÊNCIAS}

1. Tavares EO, Buriola AA, Santos JAT, Ballani TSL, Oliveira MLF. Fatores associados à intoxicação infantil. Esc. Anna Nery. [Internet] 2013; 17(1) [acesso em 12 jan 2014]. Disponível: http://dx.doi.org/10.1590/S141481452013000100005

2. Santos BZ, Grosseman S, Silva JYB, Cordeiro MMR, Bosco VL. Injúrias não-intencionais na infância: estudo piloto com mães que frequentam a clínica de bebês da Universidade Federal de Santa Catarina, Brasil. Pesqui. bras. odontopediatria clin. integr. [Internet] 2010; 10(2) [acesso em 09 jan 2014]. Disponível: http:// www.redalyc.org/pdf/637/63716962004.pdf

3. Malta DC, Mascarenhas MDM, Silva MMA, Macário EM. Perfil dos atendimentos de emergência por acidentes envolvendo crianças menores de dez anos - Brasil, 2006 a 2007. Cienc. saude colet. [Internet] 2009; 14(5) [acesso em 13 jan 2014]. Disponível: http:// dx.doi.org/10.1590/S1413-81232009000500008

4. Mutto M, Lawoko S, Nansamba C, Ovuga E, Svanstrom L. Unintentional childhood injury patterns, odds, and outcomes in Kampala City: an analysis of surveillance data from the National Pediatric Emergency Unit. J Inj Violence Res. [Internet] 2011; 3(1): 13-8, [acesso em 10 mar 2014]. Disponível: http:// dx.doi.org/10.5249\%2Fjivr.v3i1.56

5. Costa AM, Sá A, Fraga J, Dias F, Serafino MJ. Prevenção de Acidentes: o que sabem os pais. Nascer e Crescer. [Internet] 2011; 20(4) [acesso em 11 jan 2014]. Disponível: http://www.scielo.gpeari. mctes.pt/scielo.php?script=sci_arttext\&pid=S087207542011000400002\&lng=pt

6. Martins CBG, Andrade SM. Estudo descritivo de quedas entre menores de 15 anos no município de Londrina (PR, Brasil). Cienc. saude colet. [Internet] 2010; 15 Suppl 2 [acesso em 12 jan 2014]. Disponível: http://dx.doi.org/10.1590/S1413-81232010000800021

7. Santana JCB, Vasconcelos AL, Martins CV, Barros JV, Soares JM, Dutra BS. Agente comunitário de saúde: percepções na estratégia saúde da família. Cogitare enferm. [Internet] 2009; 14(4) [acesso em 17 jan 2014]. Disponível: http://dx.doi.org/10.5380\%2Fce.v14i4.16377
8. Thiollent M. Metodologia da Pesquisa-Ação.18 ${ }^{\mathrm{a}}$ ed. São Paulo: Cortez; 2011.

9. Bardin L. Análise de conteúdo. São Paulo: Edições 70; 2011.

10. Ministério da Saúde (BR). Conselho Nacional de Saúde. Diretrizes e normas regulamentadoras de pesquisa envolvendo seres humanos. Resolução n. 466, de 12 de dezembro de 2012. Brasília; 2012.

11. De Lima RP, Barbosa $X L$, Silva JE, Vieira LJES, Oriá MOB. Acidentes na infância: local de ocorrência e condutas dos familiares no âmbito domiciliar. Enferm. glob. [Internet] 2009; (15) [acesso em 05 mai 2014]. Disponível: http://scielo.isciii.es/scielo.php?script=sci_ arttext\&pid=S1695-61412009000100011\&lng=es

12. Neto CM, Alves NC, Paes MSL. Risco de acidentes na infância em uma creche comunitária de Ipatinga/ MG. Revista Enfermagem Integrada. [Internet] 2010; 3(1) [acesso em 05 mai 2014]. Disponível: http://www. unilestemg.br/enfermagemintegrada/artigo/v3/02risco-acidentes-infancia-creche.pdf

13. Gimeniz-Paschoal SR, Pereira DM, Nascimento EN. Efeito de ação educativa sobre o conhecimento de familiares a respeito de queimaduras infantis em ambiente doméstico. Rev. Latino-Am. Enfermagem. [Internet] 2009; 17(3) [acesso em 09 mai 2014]. Disponível: http://dx.doi.org/10.1590/S010411692009000300010

14. Sociedade Brasileira de Pediatria. Campanha: Acidentes e Violência são Evitáveis. [Internet] 2014 [acesso em 09 mai 2014]. Disponível: http://www. sbp.com.br/show_item2.cfm?id_categoria=90\&id_ detalhe=356\&tipo_detalhe $=\mathrm{s}$

15. Ministério da Saúde (BR). Secretaria de Atenção à Saúde. Departamento de Atenção Básica. Guia Prático do Agente Comunitário de Saúde. [Internet] 2009 [acesso em 04 mai 2014]. Disponível: http://dab.saude. gov.br/docs/publicacoes/geral/guia_acs.pdf

16. Ministério da Saúde (BR). Secretaria de Atenção à Saúde. Departamento de Atenção Especializada. Cartilha para tratamento de emergência das queimaduras. [Internet] 2012 [acesso em 01 abr 2014]. Disponível: http://sbqueimaduras.org.br/wp/ wp-content/uploads/2013/04/Cartilha_MS_2012.pdf

17. Gonçalves MEP, Cardoso SR, Rodrigues AJ. Corpo estranho em via aérea. Pulmão RJ [Internet] 2011; 20(2) [acesso em 11 mai 2014]. Disponível: http://sopterj. com.br/profissionais/_revista/2011/n_02/full.pdf

18. Silva CCA, Rosário DF, Coelho NG, Silveira CA, Paiva SMA. O agente comunitário de saúde: conhecimento e condições em uma cidade de Minas Gerais, Brasil. Rev enferm UFPE on line. [Internet] 2010; 4(3) [acesso em 19 set 2014]. Disponível: http://www.revista. 
ufpe.br/revistaenfermagem/index.php/revista/article/ viewFile/1222/pdf_151

19. Modesto MSA, Grillo LP, Próspero ENS, Mariath AB. Avaliação de curso técnico de agente comunitário de saúde sob a ótica dos egressos. Trab. educ. saúde [Internet] 2012; 10 (3) [acesso em 19 set 2014]. Disponível: http://dx.doi.org/10.1590/S198177462012000300003

20. Merhy EE, Franco TB. Programa Saúde da Família: somos contra ou a favor? Saúde em debate. [Internet]. 2002; 26(60) [acesso em 04 abr 2014]. Disponível: http:// www.eeaac.uff.br/professores/merhy/indexados-09. pdf

21. Ventorini JAO, Badke MR, Cogo SB, Cosentino SF, Santos VO. Conhecimentos e conduta dos agentes comunitários de saúde frente aos primeiros socorros. REUFSM. [Internet] 2012; 2(2) [acesso em 19 set 2014]. Disponível: http://cascavel.ufsm.br/revistas/ojs-2.2.2/ index.php/reufsm/article/view/5232

22. Martins J, Veríssimo MLOR, Oliveira MA. Avaliação dos instrumentos do projeto "nossas crianças: janelas de oportunidades", segundo agentes comunitários de saúde. Texto \& contexto enferm. [Internet] 2008; 17(1) [acesso em 16 set 2014]. Disponível: http://dx.doi. org/10.1590/S0104-07072008000100012

23. Alexandre AMC, Labronici LM, Maftum MA, Mazza VA. Map of the family social support network for the promotion of child development. Rev. Esc. Enferm. USP. [Internet] 2012; 46(2) [acesso em 16 set 2014]. Disponível: http://dx.doi.org/10.1590/S008062342012000200002 